\title{
Wind Turbine Operation in Power Systems and Grid Connection Requirements
}

\author{
A. Sudrià ${ }^{1}$, M. Chindris ${ }^{2}$, A. Sumper ${ }^{1}$, G. Gross ${ }^{1}$ and F. Ferrer ${ }^{1}$ \\ ${ }^{1}$ Centre for Technological Innovation in Static Converters and Drives \\ CITCEA, Universitat Politècnica de Catalunya \\ Av. Diagonal, 647. Pavelló A; 08028 Barcelona (Spain) \\ phone:+34 9340167 27, fax:+34 9340174 33, \\ e-mail: sudria@citcea.upc.es; \\ ${ }^{2}$ Electrical Power System Department \\ Technical University of Cluj-Napoca \\ 15, C. Daicoviciu St., 3400 Cluj-Napoca (Romania) \\ phone: +400264401451 , fax: +40264592055
}

\begin{abstract}
.
This paper discusses the impact of wind turbine generation systems operation connected to power systems, and describes the main power quality parameters and requirements on such generations.

Furthermore, it deals with the complexities of modeling wind turbine generation systems connected to the power grid, i.e. modeling of electrical, mechanical and aerodynamic components of the wind turbine system, including the active and reactive power control. In order to analyze power quality phenomena related to wind power generation, digital computer simulation is required to solve the complex differential equations.

Other important factors analyzed in this paper are grid connection requirements for connecting large wind farms to the power grid, specified by system operators all over Europe. The requirements, which include voltage and frequency stability, the ability to supply reactive power and responses to fault conditions, and active power control and power factor, are compared by the most important European wind power producers. Finally, a methodology for impact determination is proposed.
\end{abstract}

\section{Key words}

Power system simulations, Wind power generation, wind power modeling, grid code, connection requirements

\section{Introduction}

The total capacity of installed wind turbine generator systems is continuously increasing in Europe. Most of them are located in Germany, and Spain is second in wind generation penetration in Europe. EU energy policy has determined to archive in $201060.000 \mathrm{MW}$ and in $2020150.000 \mathrm{MW}$ of installed wind power. This means that wind power energy is a factor to consider in power system operation for the years to come. Thanks to the new technology achieved in power electronics, wind power turbines are able to modify active and reactive power independently, and so they are able to be an active part of the power system.

Unlike classical sources of energy, wind turbine generation systems supply real power variations into the upstream grid, and at the same time, in some types of wind turbine generation systems, the reactive power consumption is related to the real power production. These power variations cause voltage variations with consequences for the electrical power system and the customers (e.g. flicker). On the other hand, the increasing use of power electronics in wind turbine generation systems introduces voltages and current harmonics into the power system. As wind energy is a non-controllable energy source, it can cause problems with voltage stability and transient stability. Due to the rapid increase in the number of wind turbine generators connected to the grid, the increasing rate of power of single wind turbines and the weakness of the upstream power grid, where the wind turbine connects, the importance and necessity of the analysis of wind turbine systems connected to power systems is clear. 


\section{A methodology for compatibility evaluation of wind generation integration in power systems}

The total capacity of wind turbine generation in Europe has reached $28835 \mathrm{MW}$. Germany is leading statistics with 14609 MW, followed by Spain with 6202 MW and Denmark with 3115 MW [1]. The exponential growth of the number of wind generators, the continuous increase of the rate of power of single turbines and the particular generation condition of wind turbines makes evaluation of the compatibility of wind generators and the power systems necessary.

In order to analyze wind generation compatibility in power systems four factors may be taken in account (Fig.1):

- Electrical power system characteristics

- Wind turbine technology

- Grid connection requirements

- Simulation tools

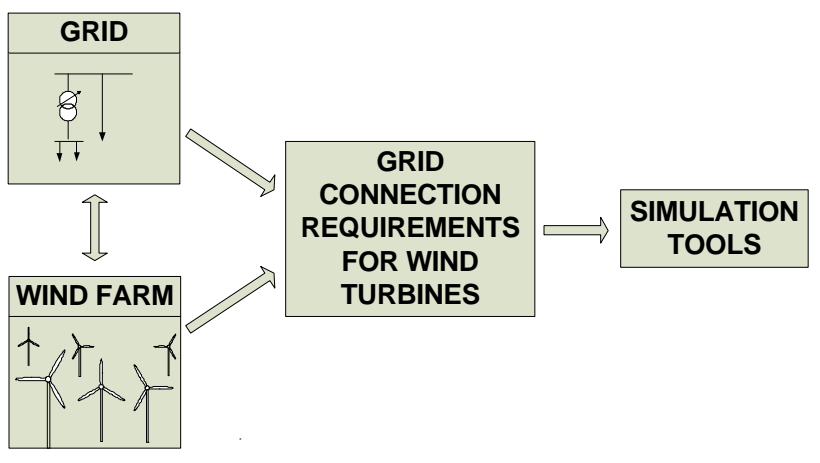

Fig. 1: Evaluation methodology of wind turbine generation and power system compatibility

\section{A. Electrical power system characteristics}

The characteristic of the power system, where the wind generation is connected to, influences highly the impact on system power quality. System voltage, short circuit power, line impedances are some of the most important characteristics that limit the network capability to admit wind power generation. For detailed analysis of impact of wind power, knowledge of the electrical power system is absolutely necessary.

Usually, wind power generation is located in regions that have favorable wind conditions, low urbanization and a weakly developed distribution and transport power network.

\section{B. Wind turbine technology}

Wind turbines transform the power from the wind to rotating mechanical power. This mechanical power is present in low-speed and high-torque power; in order to convert this power efficiently in electrical power usually a gearbox is used to transform it in high-speed mechanical power. The conversion into electrical energy is done by a generator, usually an induction machine. The asynchronous generator can be operated by fixed speed (squirrel cage) or variable speed (double fed asynchronous machine). Between the grid and the generator, a power converter can be inserted. Besides this typical wind turbine setup, other technical setups are possible: solutions with and without gearbox as well as solutions with or without power electronic conversion. The electrical output can either be ac or dc and a power converter can be used as an interface to the grid.

Applications of power electronics in wind turbine generation systems are greatly improving wind turbine behavior and performance. They are able to act as a contributor to the frequency and voltage control by means of active and reactive power control. [2]

The impact of wind generation in power systems depends on the used technology, the structure of the internal distribution network in the park, the control mechanism of each wind turbine and the overall control of the wind farm. All these factors should be known in order to analyze the impact on the power quality parameters at the connected grid.

\section{Operation limits through grid connection requirements}

In order to evaluate the impact of a wind generation to its connected power system network, grid connection requirements and limits for power quality impact are established. The objective is to fix limits in which an operation of wind generation is considered safe for system operators. If these limits are exceeded, it means that in some circumstances the power system can become instable and other connection strategies should considered.

\section{Simulation tools}

Once operations limits have been defined, the impact has to be analyzed by suitable simulation tools. The most complex task in this step is accurate modeling of the wind farm.

\section{Grid connection requirements}

The connection of wind generation to electrical power systems influences the system operation point, the load flow of real and reactive power, nodal voltages and power losses. At the same time, wind power generation has characteristics with a wide spectrum of influence [3]:

- Location in the power system

- Voltage variation of amplitude and frequency

- Flicker

- Harmonics

- Short circuit currents and protection systems

- Stability

- Self-excitation of asynchronous generators

- Real power losses

The rising impact of wind power generation in power systems causes system operators to extend grid connection requirements in order to ensure its correct operation. We can divide grid connection requirements into two categories: 
1. General grid code requirements

2. Special requirements for wind generation

The first category represents requirements valid for every generator in the grid; these are general requirements regarding the system operation point. Some of the most important requirements are:

- Steady state voltage variation

- Line capacity

- Short circuit power at the connection point

- Frequency variations

- Protection

- Contingency

Special requirements for wind generation were introduced to insert wind power generation in the power system without an impact on power quality or system stability. There are two different types of requirements: requirements established by system operators and national or international standards. A comparison of the first set is presented in the following section, where active power control, frequency limitations, reactive power control and fault ride through capability are analyzed.

Active power control is required in order to limit overproduction of wind power that can lead to instabilities due to island conditions (for example Denmark). New wind turbine technologies also allow its participation in frequency regulation.

Frequency in the power system is an indicator of the balance between production and consumption. For normal power system operation, frequency is stable and close to its nominal value. In the UTCE area the frequency is usually between $50 \pm 0.1 \mathrm{~Hz}$ and falls out of 49- $50.3 \mathrm{~Hz}$ range very seldom during major faults in the UTCE system.

The control of reactive power at the generators is used in order to keep the voltage within the required limits and avoid voltage stability problems. Wind generation should also contribute to voltage regulation in the system; the requirements either concern a certain voltage range that should be maintained at the point of connection or certain reactive power compensation that should be provided.

Until now, in case of short-circuits or instability of the grid, the wind parks disconnected immediately from the power system. Due to the high penetration of wind generation, system operators observe a certain risk for the system stability during major disconnections. Therefore, in the new regulations require that wind farms stay connected during a line voltage fault and participate in recovery from the fault.

National and international standards are applied to wind power generation regarding power quality issues for the emission of disturbances in the power system by wind generators. General standards regarding power quality, like EN 50160, are used as well as particular wind turbine ones, like IEC 61400-21. This standard defines the measurement and assessment of power quality characteristics of grid-connected wind turbines and is widely accepted by wind turbine manufacturers and utilities. The power quality is assessed by considering power system parameters (short circuit power, ${ }_{k}$ ) and wind turbine parameters, evaluated by test laboratories through empiric measurements.

\section{International comparison of grid connection requirements for wind farms}

In this section the most important aspects of connection requirements of transmission system operators of the three countries with the largest wind power production (Germany, Spain and Denmark) were presented. For Germany the network requirements of E.ON Netz, for Spain the requirements of Red Eléctrica Española (REE) and for Denmark the Eltra requirements were analyzed, discussed and compared. These requirements generally treat minimum requirements established by the transmission system operator to ensure the properties essential for wind farm operation in power systems regarding security of supply, reliability and power quality.

Eltra is the transmission system operator of the western Denmark area and its requirements are applied to transmission networks with voltage levels above $100 \mathrm{kV}$. [4].

E.ON Netz is one of five German transmission operators which set the requirements for connection of wind power to their networks. Some are general requirements for power producer and some are special requirements for wind farm integration in the power system. The requirements are applied to wind farm connections to high voltage networks $(60,110 \mathrm{kV})$ and extra high voltage networks $220 \mathrm{kV}, 380 \mathrm{kV})$. [5]

$\mathrm{REE}$ is responsible for the transmission network (220 and $400 \mathrm{kV}$ ) and for operation of the Spanish electricity system. The connection requirements for power producer are defined in procedures of operation (procedimientos de operación) and in the new royal decree RD 436/2004. [9] [10]

\section{A. Eltra (Denmark) [6]}

Active Power. Active power control is obligatory. It must be possible to reduce power to less than $20 \%$ of nominal power within less than 2 seconds. This translates to a ramp of $40 \%$ reduction per second. During a transient fault situation, the full power must halt and a subsequent power increase must be possible within approximately 30 seconds.

Frequency. Frequency operation is allowed between 49 and $50.3 \mathrm{~Hz}$ and beyond the outer limits of 47 and $53 \mathrm{~Hz}$ the turbines have to disconnect within $300 \mathrm{~ms}$.

Reactive Power. Wind farms are required at the grid connection point to provide reactive power at any operating point $(\mathrm{PF}=1)$. Depending on the system voltage, voltage reduction can be required.

Fault ride through. Wind farms have to stay connected and stable under permanent 3-phase faults and transient 2-phase fault, on any arbitrary line. The wind farm must 
be controllable for up to 3 faults within 2 minutes or up to 6 faults if the delay between the faults is 5 minutes.

\section{B. E.ON Netz (Germany) [7] [8]}

Active Power. E.ON requires a ramp rate of at least $10 \%$ of nominal power per minute for active power reduction. This should be realized without disconnection of single turbines from the grid.

Frequency. Immediate disconnection within $200 \mathrm{~ms}$ is required if the frequency falls below the limits of $47.5 \mathrm{~Hz}$ or rises above $51.5 \mathrm{~Hz}$.

Reactive Power. Wind farms rated $100 \mathrm{MW}$ or more have to be able to operate at power factor between 0.975 lagging and 0.975 leading. E.ON can demand reactive power regulation in this range.

Fault ride through. If the grid voltage at the connection point of the wind farm drops, disconnection must occur after 3 seconds minimum and after 5 seconds maximum. A voltage dip of a deep of $15 \%$ during $600 \mathrm{~ms}$ and $60 \%$ during $3 \mathrm{~s}$ must not lead to instability of the wind farm. Figure 2 shows the borderline of the system voltage explaining the voltage dip ride through capability. Above the borderline, the wind park must stay connected and below this line the disconnection of the wind park is permitted.

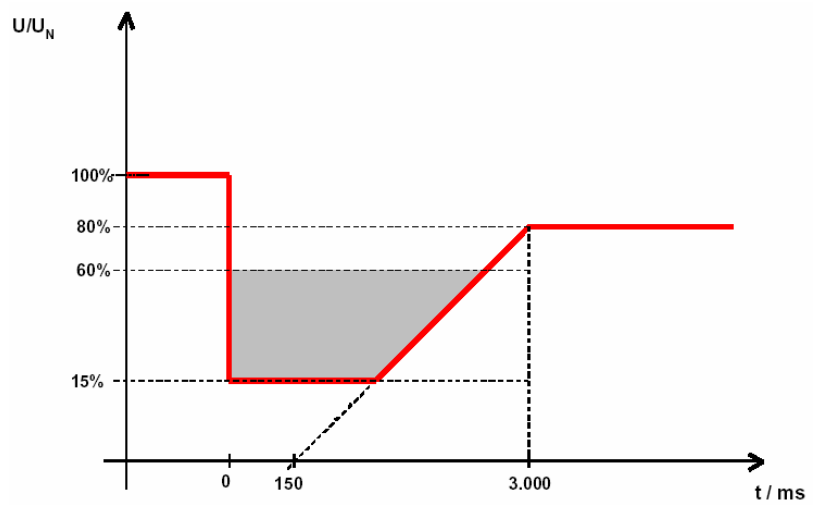

Fig. 2: Voltage dip ride through capability proposed by E.ON Netz to be supported by the wind turbines without disconnection from the grid

\section{REE (Spain) [9] [10]}

Active Power. No active power regulation is demanded, wind farms can participate in primary and tertiary regulation.

Frequency. Spain is part of the UTCE and its criteria for the frequency regulation are applied. The protection limits for under and over frequency are $49 \mathrm{~Hz}$ and $51 \mathrm{~Hz}$, respectively, the disconnection must be realized within $100 \mathrm{~ms}$.

Reactive Power. Until now, the Spanish legislation established that wind generators had to supply their produced energy with power factor one in order to obtain a bonus of $4 \%$. In the new royal decree, a bonus of up to
$8 \%$, applied to the produced $\mathrm{kWh}$ can be achieved by wind power producers when reactive power to support the grid is realized. This bonus is based on time tables were a power factor and the bonus is given. Table I shows the complement proposed by REE to wind farms being able to control their reactive power.

TABLE I. - Complement proposed by REE for wind power generation with reactive power control

\begin{tabular}{|c|c|c|c|c|}
\hline \multicolumn{5}{|c|}{ Reactive Power Complement } \\
\hline & \multirow{2}{*}{ Power Factor } & \multicolumn{3}{|c|}{ Bonus in $\%$} \\
\hline & & Peak & Plain & Vale \\
\hline \multirow{5}{*}{ 으 } & $<0.95$ & -4 & -4 & 8 \\
\hline & $<0.96$ and $=0.95$ & -3 & 0 & 6 \\
\hline & $<0.97$ and $=0.96$ & -2 & 0 & 4 \\
\hline & $<0.98$ and $=0.97$ & -1 & 0 & 2 \\
\hline & $<1$ and $=0.98$ & 0 & 2 & 0 \\
\hline & 1 & 0 & 4 & 0 \\
\hline \multirow{5}{*}{ త্তি } & $<1$ and $=0.98$ & 0 & 2 & 0 \\
\hline & $<0.98$ and $=0.97$ & 2 & 0 & -1 \\
\hline & $<0.97$ and $=0.96$ & 4 & 0 & -2 \\
\hline & $<0.96$ and $=0.95$ & 6 & 0 & -3 \\
\hline & $<0.95$ & 8 & -4 & -4 \\
\hline
\end{tabular}

Fault ride through. REE demands in the new royal decree that wind power producers should not disconnect their wind turbines during defined fault conditions. Until now, a similar voltage dip ride through characteristic like E.ON is proposed, but there is no definitive one established. Once the characteristics are defined, a bonus system will be established. Figure 3 shows one of the proposals for a voltage dip ride through capability of wind turbines.

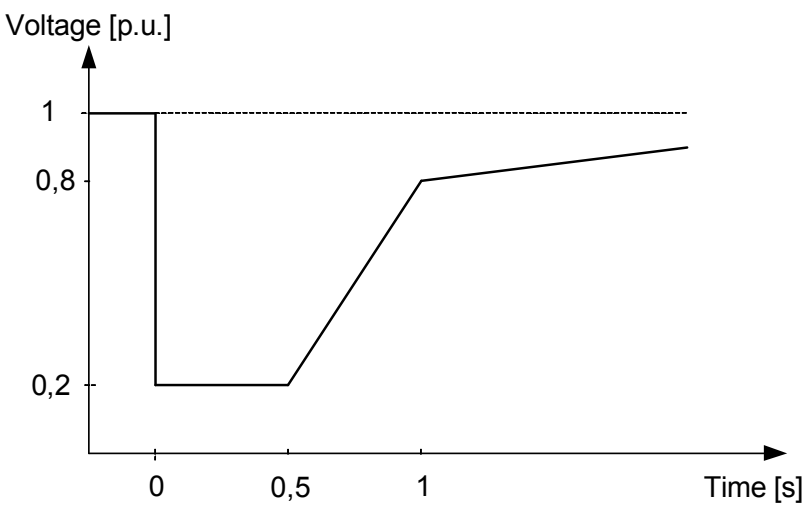

Fig. 3: Voltage dip ride through capability proposed by REE to be supported by the wind turbines without disconnection from the grid

\section{Wind turbine systems modeling}

Depending on the purpose of the analysis to be done, the required level of detail in the representation of the components of the system will vary, specific simulation software, models, and simplifications are necessary in order to obtain valid and accurate simulation results. 
The first step is to state the problem and to define a set of parameters to be analyzed given the grid connection requirements. After that, the simulation tool, suitable to analyze the stated problem and to give the requested results must be chosen. After choosing the convenient simulation software, modeling of the wind turbine and power grid components should be carried out.

Wind farms consist of many relatively small generation units. Two different models could be applied to the wind farm modeling: Separated modeling of all small generation units or aggregation of these many generators to one representative wind farm model.

Wind turbines use two different models: static models and dynamic models. Static models are needed to analyze all types of steady state analysis. Usually, these models are simple and easy to create. Dynamic models are needed for various types of analysis related to system dynamics, control analysis, optimization etc. Two different types of dynamic models are used: functional and mathematical physical models. The difference between them is that the latter one includes a detailed power electronics model [3]. Table II compares model and analysis type.

To analyze variable speed wind turbines, the following points should be considered:

- Power electronic converters and controls may be aggregated along with the generators electrical part.

- Generator inertia, aerodynamics and pitch controllers should be modeled individually.

Many of the commercial tools already contain generic wind turbine models, which are sufficiently accurate generic models for general studies focusing on wind farms.

As always with modeling and simulation, results should be verified by available data and measurements.

TABLE II. - Model types versus analysis types [3]

\begin{tabular}{|c|c|}
\hline Model & Type of analysis \\
\hline \multirow{2}{*}{$\begin{array}{c}\text { Steady state- } \\
\text { static models }\end{array}$} & Analysis of voltage variation \\
\cline { 2 - 2 } & Analysis of load flow \\
\cline { 2 - 2 } & Analysis of short-circuits \\
\cline { 2 - 2 } Transient state- & Analysis of transient stability \\
\cline { 2 - 2 } dynamic models- & Analysis of small-signal stability \\
\cline { 2 - 2 } functional models & Analysis of transient response \\
\cline { 2 - 2 } & Analysis of steady-state waveforms \\
\cline { 2 - 2 } & Synthesis of control \\
\hline \multirow{2}{*}{$\begin{array}{c}\text { Transient state- } \\
\text { dynamic models- } \\
\text { mathematical }\end{array}$} & Onalysis of start-up transient effects \\
\cline { 2 - 2 } physical models & Analysis of load transient effects \\
\cline { 2 - 2 } (power electronics) & Analysis of fault operation \\
\cline { 2 - 2 } & Analysis of harmonics and subharmonics \\
\cline { 2 - 2 } & Detailed synthesis of control \\
\cline { 2 - 2 } & Detailed optimization \\
\hline
\end{tabular}

\section{Conclusion}

Since the penetration of wind power generation is growing, system operators have an increasing interest in analyzing the impact of wind power on the connected power system. For this reason, grid connection requirements are established. In the last few years, the connection requirements have incorporated, in addition to steady state problems, dynamic requirements, like voltage dip ride through capability. This leads to the need for a detailed modeling of wind turbine systems in order to analyze the dynamic phenomena in the power grid.

Moreover, new wind turbine technology integrates power electronics and control making it possible for wind power generation to participate in active and passive power control. Thus, exact modeling of wind turbine systems is required, in order to simulate wind turbine behavior during the modification of the network operation point.

\section{References}

[1] http://windpower-monthly.com/windicator

[2] Blaabjerg, F., Wind Power - A Power Source Enabled by Power Electronics; 2004 CPES Power Electronics Seminar and Industry Research Review, April 18-20, Virginia Tech, Blacksburg, VA

[3] Z. Lubosny; Wind Turbine Operation in Electric Power Systems; Springer-Verlag Berlin, ISBN 3540-40340-X

[4] Matevosyan, J., Ackerman, T., Bolik S., Lennart, S. Comparison of international regulations for connection of wind turbines to the network. Nordic wind power conference, 1-2 march, 2004.

[5] Jauch, C., Sorensen, P., Bak-Jensen, B. International review of grid connection requirements for wind turbines. Nordic wind power conference, 1-2 march, 2004.

[6] Eltra Specifications for connecting wind Farms to the Transmission; 26. April 2000; Doc Nr. 74557; Case Nr. 303.126.1351

[7] E.ON Netz GmbH; Ergänzende Netzanschlussregeln für Windenergieanlagen Stand: 01. Dezember 2001

[8] EON Netz GmH; Grid code for High and Extra High Voltage, Status 1. August 2003

[9] RD 436/2004 de 12 Marzo por el que se establece la metodología para la actualización y sistematización del régimen jurídico y económico de la actividad de producción de energía eléctrica en régimen especial. BOE num.75; 27. March 2004, pg. 13217

[10] http://www.ree.es/index_ope.html; Submenu: Operación del Sistema Eléctrico/Procedimientos de operación 